\title{
Adaptation of pulmonary receptors in the spontaneously breathing anaesthetized rat
}

\author{
A. Davies, L. Pirie, R.A. Eyre-Todd
}

\begin{abstract}
Adaptation of pulmonary receptors in the spontaneously breathing anaesthetized rat A. Davies, L. Pirie, R.A. Eyre-Todd. CERS Journals Ltd 1996.

ABSTRACT: It has been suggested that species with high breathing frequencies have pulmonary stretch receptors which adapt more rapidly than species with low breathing frequencies. This has proved not to be so. Our hypothesis is that this theory is in fact correct if modified so that overall rate of adaptation of afferent vagal activity, i.e. the sum of stretch and rapidly adapting receptors, is considered. A rapidly breathing species, such as the rat, would thus have a greater proportion of rapidly adapting receptors, than a more slowly breathing species.

To test this hypothesis, we measured the proportion of rapidly adapting pulmonary mechanoreceptors in spontaneously breathing rats for comparison with existing results from more slowly breathing species.

We found there to be one rapidly adapting receptor for every three slowly adapting receptors present. This measurement has not previously been made in spontaneously breathing rats. The ratio of rapidly to slowly adapting pulmonary receptors in the species sequence cat-rabbit-rat is the same as the ratio of their breathing frequencies $(3: 4: 10)$.

We propose that the difference in proportion of slowly to rapidly adapting pulmonary receptors in different species may be related to their eupnoeic breathing frequency.
\end{abstract}

Eur Respir J., 1996, 9, 1637-1642.

BARTLETT and ST John [1] made the important observation that adaptation of pulmonary mechanoreceptors imbues them with dynamic as well as static response characteristics. It would, thus, seem important to consider the degree of adaptation that takes place in a time interval similar to the animal's respiratory frequency. BARTLETT and $\mathrm{ST}_{\mathrm{T}}$ John [1] postulated that pulmonary stretch receptors (PSRs) of species with different eupnoeic frequencies would have different rates of adaptation to accurately signal lung conditions. This did not prove to be the case from their results. However, their observations were restricted to pulmonary stretch receptors.

Rapidly adapting receptors (RARs), sometimes called "irritant" or "deflation" receptors, are found in the lungs of many species [2]. It is possible that a change in the proportion of these receptors, relative to the number of PSRs, provides the different degree of adaptation required. The important concept of a link between receptor adaptation rate and frequency of eupnoeic breathing is linked to the role of PSRs and RARs in control of breathing. It is generally accepted that PSRs terminate inspiration and extend expiration. We have demonstrated [3] that RARs terminate expiration, and hence can profoundly affect breathing frequency. We have excluded C-fibre receptors from the present study because there is, as yet, insufficient quantitative description of their activity to enable between species comparison to be made.

Two recent publications $[4,5]$ have reported the activity of pulmonary receptors in anaesthetized, paralysed, open- and closed-chested rats, ventilated by positive pressure. These authors report very little RAR activity. If this were true for intact spontaneously breathing rats, it would oppose the theory that small mammals with high respiratory rates have a higher proportion of rapidly adapting lung receptors.

We have used the rat as a model of respiratory control in human lung disease [6]. If the rat is to be a useful model in this context, it is important to know whether results obtained can be compared with those obtained in cats dogs and rabbits $[3,7,8]$.

There is, as yet, insufficient evidence from a wide variety of species to give a categorical answer to the question of whether RAR have the same function in rats as in other species. However, drawing a parallel with PSRs, the Hering Breuer inflation reflex in all species, although varying in strength between species, is in all cases attributed to PSRs. Also, the way in which the number of receptors of a certain type in a species is determined needs to be considered and depends on the definition used. The overlap of the conduction velocities in fibres from PSRs and RARs tends to make categorization by this criterion difficult. However, these differences in definition only become important when considering subgroups of RARs and PSRs. In our experience with rabbits [3] and rats, the functional difference is unambiguous.

To determine whether the reported absence of RARs in rats was due to the nature of the preparation or a true species difference, and to measure the proportion of RARs 
present, we recorded the activity of pulmonary receptors in closed-chested, spontaneously breathing rats during eupnoea, and during activity provoked by inflation of the lungs.

\section{Methods}

\section{Animals and preparation}

Fifteen barrier reared Sprague-Dawley rats, weighing $564 \pm 21.4 \mathrm{~g}$, were anaesthetized with an intraperitoneal injection of $1.5 \mathrm{~g} \cdot \mathrm{kg}^{-1}$ urethane as a $25 \%$ solution, supplemented as necessary via a catheter in the left femoral vein. A short tracheal cannula was inserted and airflow recorded by a Fleisch pneumotachograph head and Mercury CS5 differential pressure transducer. The left vagus nerve was cut high in the neck and the distal cut end placed in a copper tray filled with liquid paraffin. "Single fibre" preparations were made from strands of nerve that displayed respiratory rhythm when placed on a pair of silver wire electrodes. Carbon dioxide in the respired air was monitored by a Beckman L.B.1 gas analyser.

\section{Experimental method}

A period of eupnoeic breathing was recorded. The rat's lungs were then inflated four times with 0.5 and $1 \mathrm{kPa}$ airway pressure. Three minutes separated the inflations, which were administered by the method of DAVIES and Roumy [3]. This consisted of having a solenoid operated valve very rapidly connect the tracheal cannula from the atmosphere to a $50 \mathrm{~L}$ drum maintained at the required pressure. Inflation was synchronized with the peak of inspiration as detected by zero flow. Positive pressure was maintained until the rat took a spontaneous inspiration.

\section{Recording}

Electrical activity of the single fibre preparations was amplified by a high-gain RC amplifier (Neurolog), fed to an audio-amplifier and loudspeaker and recorded directly, and as transistor-transistor logic (TTL) pulses, together with the other physiological variables, by a TEAC XR-30 recorder.

Records were taken for four breaths before applying the step in pressure, and for 2-3 s after the first inspiratory effort.

\section{Analysis}

Analysis was undertaken "off-line" by digitizing the tape records via a Cambridge Electronics Design 1401 converter; and using a modified proprietary computer analysis program (Cambridge Electronics Design Spike 2).

Receptors were classified as slowly or rapidly adapting. Conduction velocity was initially used to differentiate between slowly and rapidly adapting receptors, but it soon became apparent that the difference in response to a step of inflation was sufficient to clearly differentiate between the two types. Adaptation was quantified using a form of KNOwLTON and LARRABEe [7] Adaptation Index, modified to provide criteria which enabled a clear differentiation between slowly and rapidly adapting receptors, without the profound physiological interventions of paralysis or thoracotomy. Which would also have frustrated the objective of recording under eupnoeic conditions.

The number of action potentials in the third $0.25 \mathrm{~s}$ of lung inflation with a pressure of $1 \mathrm{kPa}$, was subtracted from the number in the first $0.25 \mathrm{~s}$, and the result expressed as a percentage of the number of action potentials in the first $0.25 \mathrm{~s}$ of inflation. This expression of adaptation was termed "Adaptation Index", and clearly distinguished between slowly and rapidly adapting receptors. It also involved a time interval appropriate to the rat's breathing frequency. Rapidly adapting receptors were defined as having an index of $100 \%$.

Occasionally, C-fibres, identified by their low conduction velocity, were isolated and discarded. Not all receptors, which could be clearly categorized manually as rapidly or slowly adapting, were suitable for computer analysis during inflation. The most common artifact defeating computer analysis was a second fibre discharging during inflation, which was not detected during recording.

\section{Statistics}

Statistical significance of difference between mean values, (shown as mean \pm SEM), calculated by Student's unpaired t-test was taken as a p-value less than 0.05. To ensure the maximum rigour, the mean values obtained for individual receptors were used for comparison.

a)

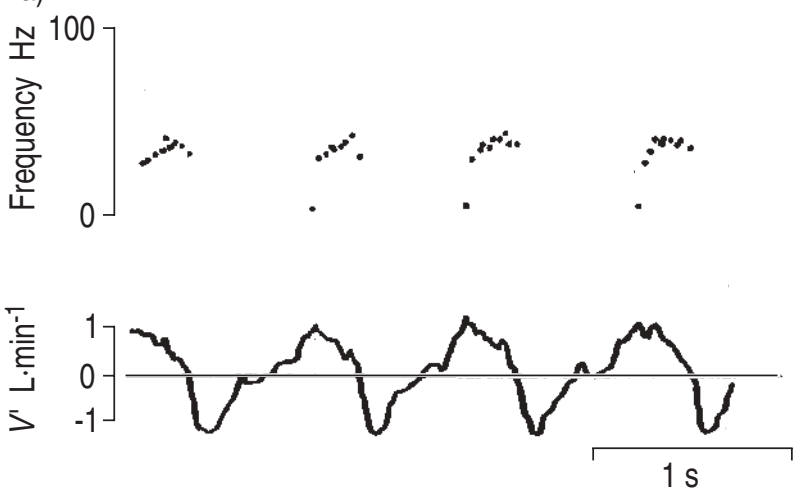

b)
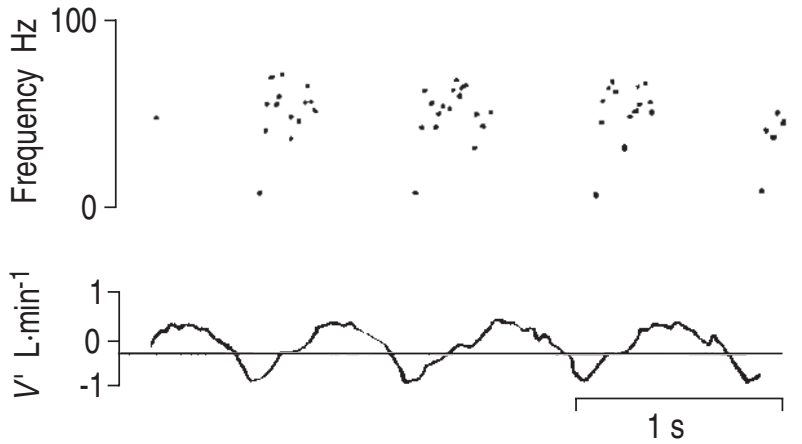

Fig. 1. - Computer record of respiratory airflow (expiration downward) and instantaneous frequency of discharge of: a) Type I PSR; b) expiratory RAR, in two rats. $V^{\prime}$ : airflow; PSR: pulmonary stretch receptor; RAR: rapidly adapting receptor. 


\section{Results}

Of the 85 receptors recorded, 12 were inadequate for later analysis. The 73 receptors characterized in this study could be divided into PSR (fig. 1a) and RAR (fig. 1b) on the criterion of the Adaptation Index described in the Methods section. All had the characteristics of receptors with myelinated fibres, when their discharge was inspected on an oscilloscope. Five fibres with discharge characteristics associated with unmyelinated fibres were abandoned.

In two rats, conduction velocity was measured in fibres firing in inspiration and seen to be slowly adapting (36.1 \pm $7.1 \cdot \mathrm{ms}^{-1} ; \mathrm{n}=8$ ) and those firing in expiration which were rapidly adapting $\left(14.6 \pm 4.6 \cdot \mathrm{ms}^{-1} ; \mathrm{n}=4\right)$.

The PSRs were divided into three types; and of these, two types, I and II, were very similar as described below. The mean adaptation index of PSR was $42.7 \pm 3.9 \%$. The mean adaptation indices of the three individual types which will be described were: type I $58.0 \pm 8.8 \%$; type II $42.6 \pm 1.8 \%$; and type III $27.5 \pm 3.8 \%$. Rapidly adapting receptors had an index of $100 \%$.

\section{Slowly adapting receptors (PSRs)}

The receptors categorised as PSRs were further divided into three types on the basis of their discharge pattern during an eupnoeic respiratory cycle of mean tidal volume $2.83 \pm 0.20 \mathrm{~mL}$.

Type I (16\% of all receptors). These 12 receptors discharged almost exclusively during mid and late inspiration as shown in figure 2. The small number of spikes (table 1a) occurring during expiration were restricted to the first $15 \%$ of expiratory duration $(t \mathrm{E})$. Their peak, mean and minimum frequencies of discharge during eupnoea with a tidal volume $(V \mathrm{~T})$ of $2.83 \pm 0.20 \mathrm{~mL}$ and their frequencies on lung inflation $(0.5$ and $1.0 \mathrm{kPa})$ are shown in tables $1 \mathrm{a}$ and 2.

Type II (41\% of all receptors). These 30 receptors were placed in a separate category from Type I because of their significantly higher discharge frequency (table 1a).

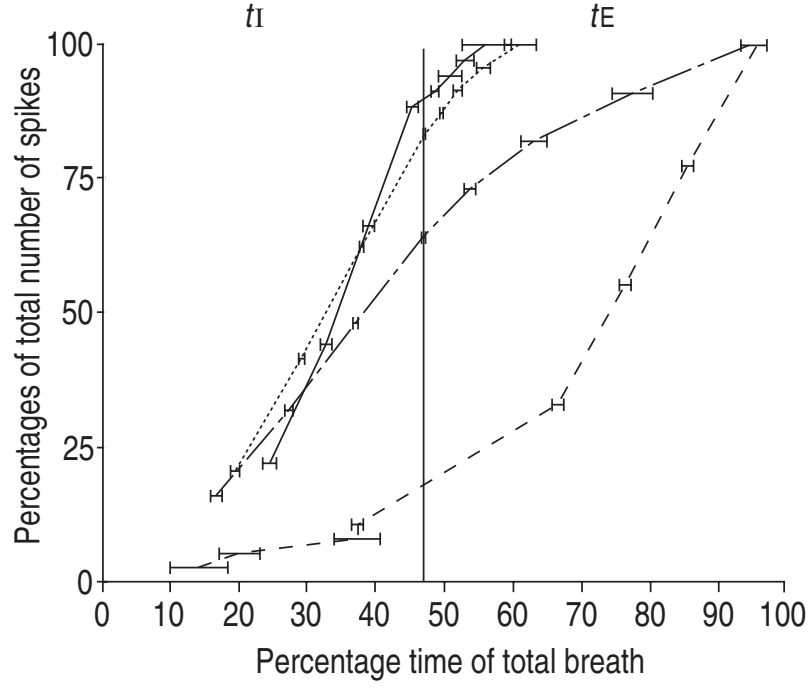

Fig. 2. - Distribution of the discharge of PSR Type I (12 receptors) PSR Type II (30 receptors), PSR Type III (9 receptors), and expiratory RARs (22) throughout a breath. The means \pm SEM of percentage of the total number of action potentials occurring at times through the respiratory cycle are shown. ㄴ. Type I; -...-.: Type II; - - - - : Type III; - - - -: RAR. $t$ I: inspiratory duration; $t \mathrm{E}$ : expiratory duration. For further abbreviations see legend to figure 1.

During expiration, their discharge was restricted to the first quarter of $t \mathrm{E}$. Thus, these receptors discharged over a somewhat greater range of the breathing cycle than Type I receptors. They were also placed in a separate category because of their lower adaptation index and significantly higher discharge frequency. Their response to eupnoea and sustained lung inflation is shown in tables $1 \mathrm{a}$ and 2.

Type III (12\% of all receptors). These nine receptors differed more clearly from Type I and II than did Type I and II from each other. They discharged throughout inspiration and into expiration, as shown in figure 2 . Their response to eupnoeic breathing and sustained lung inflation is shown in tables $1 \mathrm{a}$ and 2 .

The only purpose of dividing the PSRs into Types I, II and III was to compare them with types reported by

Table. 1. - Discharge characteristics of: a) pulmonary slowly adapting receptors and; b) rapidly adapting receptors

\begin{tabular}{|c|c|c|c|c|c|c|}
\hline $\begin{array}{l}\text { Receptor } \\
\text { type }\end{array}$ & Phase & $\begin{array}{c}\text { Receptors } \\
\text { n }\end{array}$ & $\begin{array}{c}\text { Peak } \\
\text { frequency } \\
\mathrm{Hz}\end{array}$ & $\begin{array}{c}\text { Mean } \\
\text { frequency } \\
\mathrm{Hz}\end{array}$ & $\begin{array}{c}\text { Minimum } \\
\text { frequency } \\
\mathrm{Hz}\end{array}$ & $\begin{array}{l}\text { Impulses } \\
\text { in phase }\end{array}$ \\
\hline \multicolumn{7}{|c|}{ a) Pulmonary slowly adapting receptors } \\
\hline \multirow[t]{2}{*}{ PSR I } & $t \mathrm{I}$ & 12 & $45.8 \pm 5.2$ & $20.4 \pm 2.4$ & $25.7 \pm 2.4$ & $8.3 \pm 0.82$ \\
\hline & $t \mathrm{E}$ & 12 & $5.4 \pm 3.7$ & $1.79 \pm 0.42$ & $6.4 \pm 2.5$ & $1.08 \pm 0.15$ \\
\hline \multirow[t]{2}{*}{ PSR II } & $t \mathrm{I}$ & 30 & $89.8 \pm 3.7$ & $62.7 \pm 3.6$ & $41.6 \pm 1.3$ & $24.7 \pm 1.2$ \\
\hline & $t \mathrm{E}$ & 30 & $67.6 \pm 7.5$ & $10.9 \pm 1.2$ & $34.3 \pm 2.3$ & $5.0 \pm 0.45$ \\
\hline \multirow[t]{2}{*}{ PSR III } & $t \mathrm{I}$ & 9 & $114.5 \pm 10.1$ & $74.5 \pm 7.3$ & $44.8 \pm 4.7$ & $30.2 \pm 2.7$ \\
\hline & $t \mathrm{E}$ & 9 & $92.2 \pm 8.0$ & $32.0 \pm 5.2$ & $17.3 \pm 4.2$ & $16.7 \pm 2.8$ \\
\hline \multirow[t]{2}{*}{ Mean all PSR } & $t \mathrm{I}$ & 51 & $86.1 \pm 4.4$ & $57.4 \pm 3.8$ & $40.0 \pm 1.6$ & $22.4 \pm 1.4$ \\
\hline & $t \mathrm{E}$ & 51 & $57.1 \pm 5.1$ & $13.2 \pm 2.0$ & $25.7 \pm 2.3$ & $6.0 \pm 0.99$ \\
\hline \multicolumn{7}{|c|}{ b) Rapidly adapting receptors } \\
\hline \multirow[t]{2}{*}{ RAR } & $t \mathrm{I}$ & 22 & $18.5 \pm 3.0$ & $5.0 \pm 1.3$ & $7.7 \pm 1.2$ & $1.7 \pm 0.48$ \\
\hline & $t \mathrm{E}$ & 22 & $87.5 \pm 10.4$ & $28.8 \pm 3.0$ & $18.1 \pm 2.3$ & $13.6 \pm 1.4$ \\
\hline
\end{tabular}

Mean士SEM of peak and minimum frequency of discharge $(\mathrm{Hz})$ of the four receptor types, measured from interspike interval. Mean frequency in this table = total spikes in the phase/duration of phase, and therefore can be less than minimum frequency, calculated from interspike interval. Frequencies of discharge of Types II and III receptors are significantly different $(p<0.05)$ from the mean of Type I receptors. For other criteria used to differentiate between receptor types see text. $t \mathrm{I}$ : inspiratory duration; $t \mathrm{E}$ : expiratory duration; PSR: pulmonary stretch receptor; RAR: rapidly adapting receptor. 
Table 2. - Adaptation to inflation

\begin{tabular}{|c|c|c|c|c|}
\hline \multirow{2}{*}{$\begin{array}{l}\text { Receptor } \\
\text { type }\end{array}$} & \multirow{2}{*}{$\begin{array}{c}\text { Receptors } \\
\mathrm{n}\end{array}$} & \multirow{2}{*}{$\begin{array}{l}\text { Time from } \\
\text { onset of } \\
\text { inflation } \mathrm{s}\end{array}$} & \multicolumn{2}{|c|}{ Impulses $\mathrm{n}$} \\
\hline & & & $0.5 \mathrm{kPa}$ & $1.0 \mathrm{kPa}$ \\
\hline & \multirow[t]{2}{*}{12} & 1st 0.25 & $15.8 \pm 1.2$ & $19.2 \pm 2.3$ \\
\hline & & 3rd 0.25 & $3.4 \pm 1.4$ & $8.7 \pm 2.2$ \\
\hline \multirow[t]{2}{*}{ II } & \multirow[t]{2}{*}{30} & 1st 0.25 & $25.5 \pm 2.1$ & $31.6 \pm 4.1$ \\
\hline & & 3rd 0.25 & $8.9 \pm 1.7$ & $18.3 \pm 2.6$ \\
\hline \multirow[t]{2}{*}{ III } & \multirow[t]{2}{*}{9} & 1 st 0.25 & $31.0 \pm 2.1$ & $31.7 \pm 2.2$ \\
\hline & & 3rd 0.25 & $16.3 \pm 1.3$ & $21.5 \pm 1.5$ \\
\hline
\end{tabular}

Mean \pm SEM of number of impulses (action potentials) in 1st and 3rd $0.25 \mathrm{~s}$ of lung inflations by 0.5 and $1.0 \mathrm{kPa}$ for inspiratory receptor types I, II and III. Expiratory, rapidly adating receptors, totally adapted within $0.25 \mathrm{~s}$. The adaptation indices of Type I and Type II receptors were not significantly different. The adaptation index of Type III receptors was significantly different $(\mathrm{p}<0.01)$ from the other two types.

other workers (see Discussion). The pooled values of discharge properties of all the PSRs are, therefore, given in table 1a for comparison with those of the RARs, which was the main purpose of this investigation.

\section{Rapidly adapting receptors (RARs)}

These 22 receptors (30\% of all receptors) discharged almost exclusively during expiration in eupnoeic breathing, as shown in figure 2 and table $1 \mathrm{~b}$.

Because "mean frequency" was calculated by dividing number of spikes by duration of inspiration $(t \mathrm{I})$ or expiration $(t \mathrm{E})$ it can, apparently paradoxically, be less than "minimum frequency", calculated from interspike interval.

Consistency of discharge. RARs have previously been described as irregular in their discharge. RARs in the rats used for these experiments discharged with a highly consistent pattern. Figure 3 shows the timing of 25, 50 and $100 \%$ of total discharge of two typical RARs over five consecutive breaths. Table $1 \mathrm{~b}$ shows the discharge characteristics of 22 RARs during eupnoea.

\section{Discussion}

BARTLETT and St John [1] postulated that pulmonary mechanoreceptors of animals with different eupnoeic breathing frequencies would have different rates of adaptation. This did not prove to be the case from their results. However, their observations were restricted to PSRs. Rapidly adapting receptors, sometimes called "irritant" or "deflation" receptors, are found in the lungs of many species. It may be that a change in the proportion of RARs provides the different overall degree of adaptation required by different species [9]. Information concerning rapidly adapting receptors exists for a number of species $[3,10,11]$. No information has previously been available for rats. The association of adaptation rate with frequency of breathing receives support from our earlier findings [3] that the activity of RARs profoundly affects expiration, accelerating breathing.

In considering the control of pattern of breathing, it is important to consider the degree of receptor adaptation that takes place in a time interval approximately similar

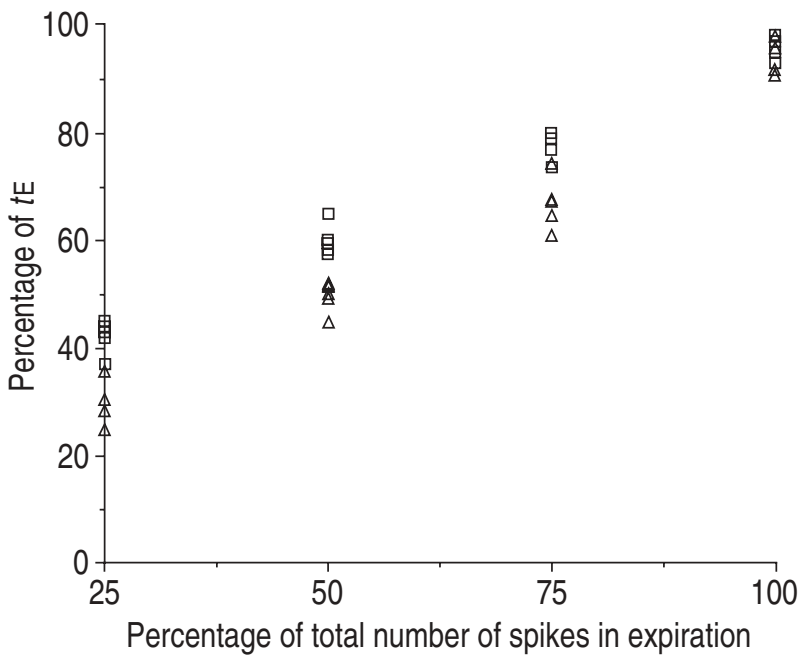

Fig. 3. - The regular nature of discharge of rapidly adapting receptors in rats, demonstrated by plotting percentage of duration of expiration $(t \mathrm{E})$ against percentage total number of spikes in expiration for five consecutive breaths for two typical rapidly adapting receptors (RARs). $\Delta$ : receptor $1 ; \square:$ receptor 2 .

to the animal's respiratory cycle. The classical Adaptation Index of KNOWLTON and LARRABEE [7] involves a $2 \mathrm{~s}$ lung inflation. A rat might take three breaths in that time. WIDDICOMBE [10] points out that such an Adaptation Index "does not distinguish between adaptation rates of endings which cease firing within $1 \mathrm{~s}$, so that stimuli well above threshold must be used and the endings must discharge for $2 \mathrm{~s}$ or more". To overcome these difficulties, we measured the degree of adaptation in $0.75 \mathrm{~s}$ of the application of a step stimulus.

Measured in the conventional open-chested preparation, rats have PSRs with adaptation indices similar to those of other species [4]. Our measure of adaptation is a more rigorous test of whether a receptor is rapidly or slowly adapting than conventional definitions. Recent publications $[4,5]$ have pointed out the paucity of information about the properties of pulmonary receptors in the rat and described discharge patterns mainly under conditions of respiratory paralysis and artificial ventilation.

We report here receptor activity measured without resort to the paralysis or thoracotomy of previous investigations, which would exclude recording under eupnoeic conditions. The difference between PSRs and RARs was very clear, and did not depend on our tentative division of PSRs into three types, undertaken for comparison with other published findings. Our findings are sufficiently similar to those reported previously to bear comparison, but differ in a number of important ways. Many differences may arise from the differences in transmural pressure found in the open- or closed-chested rats. That opening the chest affects receptor activity is clearly demonstrated in the publications by TSUBON [5] and BERGREN and PETERSON [4]. In view of the profound differences between open- and closed-chested preparations, the properties of the PSRs in the report by BERGREN and PETERSON [4] and in our results are remarkably similar. We found $24 \%$ PSRs (16\% of all receptors) to be exclusively inspiratory (Bergren and Peterson - 25\%). Fifty nine of our PSRs (41\% of all receptors) discharged throughout 
inspiration and early expiration (Bergren and Peterson $49 \%$ ). Eighteen percent of our PSRs (12\% of all receptors) discharged throughout the respiratory cycle.

As spontaneously breathing rats have respiratory frequencies of the order of 100 breaths $\mathrm{min}^{-1}$ [12] with virtually no expiratory pause, the "deflationary (D) slowly adapting receptors (SARs)" of BERGREN and PETERSON [4], which made up $18 \%$ of their SAR (PSR) population, and the "deflation sensitive receptors" of TSUBONE [5], both of which were stimulated during the deflationary phase of their ventilating pump, have little equivalence to any of our receptors. One may speculate that these receptors would approximate more closely to one of the groups that we describe, if the rats from which they were recorded were breathing spontaneously rather than paralysed and ventilated by positive pressure.

Table 1 shows peak and minimum frequency derived from interspike intervals. Mean frequency is the number of action potentials in a phase of breathing (inspiration (I) or expiration (E)) divided by the duration of that phase, and can therefore be less than minimum frequency. Figure 2 shows the phase-spanning nature of the Type III receptors, and that Type I and RAR discharges are highly polarized into inspiration and expiration, respectively. The properties of Type I and Type II receptors are very similar. We have tentatively separated them into two types, mainly on the basis of adaptation rates and eupnoeic frequencies of discharge. WIDDICOMBE [10] comments "adaptation rate alone does not distinguish between different groups of pulmonary sense organs". It may well be that further investigation will not sustain this separation, which is not central to the thesis being tested by this study.

Because the imposed ventilatory cycles of paralysed rats used by other workers was so different from the pattern of spontaneous breathing of our rats, it is difficult to make comparisons of frequency of discharge. It can be said that the total number of impulses produced by Type I PSRs, in a respiratory cycle of inspiratory duration $0.39 \pm 0.005 \mathrm{~s}$ and expiratory duration $0.43 \pm 0.013 \mathrm{~s}$ $(\mathrm{n}=60$ breaths; 12 rats) in our study, is of the same order of magnitude as all except the "mostly inspiratory" receptors reported by Bergren and Peterson [4] during a pump cycle of approximately $0.9 \mathrm{~s}$; of which approximately $0.2 \mathrm{~s}$ was occupied by inflation. As most of the activity reported by these authors took place during inflation, there is an approximation to the rate of discharge that we report. SCHOENER and Frankel [13], who used a realistic frequency $(2 \mathrm{~Hz})$ to ventilate their paralysed rats, reported a mean discharge frequency of $96 \pm 7 \mathrm{~Hz}$ for PSRs. This compares with our overall mean frequency for PSRs of $70.0 \pm 1.7$ impulses $\cdot \mathrm{s}^{-1}$ (table 1).

The algorithm that we used to measure adaptation rates of our receptors addressed the problems of matching the period investigated to a physiological breathing pattern, and the criticism by WidDICOMBE [10] of the problem of attributing an adaptation index to receptors which silenced within $1 \mathrm{~s}$ of applying inflation. Our form of index also addresses the problem of using "peak frequency" in calculating adaptation index. Peak frequency, by definition, measures the time interval between only two action potentials.

Our longer, albeit very brief, interval provides a more representative sample of receptor activity on inflation.
Our adaptation index distinguished clearly between the three types of PSRs and RARs.

Pulmonary stretch receptors respond to the degree and rate of change of volume of the lungs [14], and have been categorized into those that saturate above $1 \mathrm{kPa}$ transmural pressure and those with a more linear response. Some workers report $[15,16]$ that there is a continuum rather than discrete PSR types. Whilst this may be true for Type I and II PSRs found in our rats, these were very different in rate of adaptation and position of firing in the respiratory cycle from Type III PSRs or RARs (fig. 2 and tables 1 and 2). No attempt was made to identify the location of these receptors. Some may have been extrathoracic being active during expiratory flow [17].

In our rats, $30 \%$ of receptors active during spontaneous breathing were rapidly adapting. This is in direct contrast to BERGRen and PETERSON [4] who found only 7\% of their receptors were rapidly adapting. Tsubone [5], on the other hand, using an open-chested paralysed preparation like Bergren and Peterson [4], found "irritantlike receptors", which discharged during both inflation and deflation. The only apparent difference between the methods of these two studies was the use by Bergren and Peterson of a $0.3-0.5 \mathrm{kPa}$ end-expiratory pressure and the repeated use of exposures of 5-20s to dimethylether vapour to silence PSRs. Ether vapour stimulates RARs in guinea-pigs [18]. However, concentrations of 7.5-14.5\% inhibits RARs [10]. Because of their more central and superficial position in the airways compared with PSRs [19], it is likely that the RARs in the study by BERGREN and PETERSON [4] received higher concentrations of the vapour used repeatedly to silence PSRs than the PSRs themselves. We cannot say whether such treatment permanently silences RARs, but it may explain the difference between the results of the latter study and our findings. It might also be that the use of endexpiratory pressure prevented atelectasis, which would have caused increased activity in the RARs of Tsubone's preparation compared to those of Bergren \& Peterson.

There is a fundamental problem when comparing lung receptor activity of open-chested animals, ventilated by positive pressure, with the more physiologically normal spontaneously breathing animal. In the open-chested animal, the airways are expanded by a pressure which compresses the innermost epithelial layers against the underlying muscle. An important property of bronchial smooth muscle is that it becomes noncompliant at relatively low transpulmonary pressures (around $1 \mathrm{kPa}$ [20]). Conversely, in normal, closed-chested, spontaneously breathing animals the innermost epithelial layers are placed in a state of tension by expansion of the lung. There are no data yet available as to whether these differences activate receptors in different ways; but it could be expected that RARs, being found in the innermost lining layers, would show greater differences than PSRs located within the muscle wall. It may be that the different patterns of RAR activity, in particular the presence of irregular activity during positive-pressure inflation ([8] for example) are, in part, a result of this effect.

In conclusion, we maintain that rapidly adapting receptors do exist in considerable numbers in rats and are active during spontaneous ventilation. They are present in the ratio of approximately 1 rapidly adapting recep- 
tor to 3 pulmonary stretch receptors. This compares with ratios of 1:4 in the rabbit [11], and 1:10 in cats [10]. The breath durations of adults of these species is also in the ratio 3:4:10 [9]. This supports our suggestion (a modification of that of BARTLETT and ST JOHN [1]) that the respiratory frequency of a species is related to the overall adaptation rate of all its pulmonary receptors.

Acknowledgements: H. Brown of The Statistics Department of University of Edinburgh Department of Public Health provided expert statistical advice.

\section{References}

1. Bartlett D Jr, St John WM. Adaptation of pulmonary stretch receptors in different mammalian species. Respir Physiol 1979; 37: 303-312.

2. Sant'Ambrogio G. Nervous receptors of the tracheobronchial tree. Ann Rev Physiol 1987; 49: 611-627.

3. Davies A, Roumy M. Effect of transient stimulation of lung irritant receptors on pattern of breathing in rabbits. J Physiol (Lond) 1982; 324: 389-401.

4. Bergren DR, Peterson DF. Identification of vagal sensory receptors in the rat lung: are there subtypes of slowly adapting receptors? J Physiol(Lond) 1993; 464: 681-698.

5. Tsubone H. Characteristics of vagal afferent activity in rats: three types of pulmonary receptors responding to collapse, inflation and deflation of the lungs. Exp Neurol 1986; 92: 541-552.

6. Pirie L. A comparison of the lung reflexes in anaesthetized rats and rabbits. J Physiol 1993; 459: 356P.

7. Knowlton GC, Larrabee MG. A unitary analysis of pulmonary volume receptors. Am J Physiol 1946; 147: 100-114.
8. Sampson SR, Vidruk H. Properties of "irritant" receptors in canine lung. Respir Physiol 1975; 25: 9-22.

9. Widdicombe JG. Respiratory reflexes in man and other mammalian species. Clin Sci 1961; 21: 163-170.

10. Widdicombe JG. Receptors in the trachea and bronchi of the cat. J Physiol (Lond) 1954; 123: 71-104.

11. Roumy M, Leitner LM. Localization of stretch and deflation receptors in the airways of the rabbit. $J$ Physiol (Paris) 1980; 76: 67-70.

12. Marshall JM, Metcalfe JD. Cardiovascular changes associated with augmented breaths in normoxia and hypoxia in the rat. J Physiol 1988; 400: 15-27.

13. Schoener EP, Frankel HM. Effect of hyperthermia and $P \mathrm{a}, \mathrm{CO}_{2}$ on the slowly adapting pulmonary stretch receptor. Am J Physiol 1972; 222: 68-72.

14. Davis HL, Fowler WS, Lambert EH. Effect of volume and rate of inflation and deflation on transpulmonary pressure and response of pulmonary stretch receptors. Am J Physiol 1956; 187: 558-566.

15. Pack AI, Ogilvie MD, Davies RO, Galante RJ. Response of pulmonary stretch receptors during ramp inflations of the lung. J Appl Physiol 1986; 61: 344-352.

16. Farber JP, Fisher JT, Sant'Ambrogio G. Distribution and discharge properties of airway receptors in the opossum, Didelphus marsupialis. Am J Physiol 1983; 245: R209-214.

17. Sant'Ambrogio G, Mortola P. Behaviour of slowly adapting stretch receptors in the extrathoracic trachea of the dog. Respir Physiol 1977; 31: 377-385.

18. Bergren DR, Sampson SR. Characterization of intrapulmonary, rapidly adapting receptors of guinea-pigs. Respir Physiol 1982; 47: 83-95.

19. Jeffery P, Reid L. Intraepithelial nerves in normal rat airways: a quantitative electron microscopic study. $J$ Anat 1973; 114: 35-45.

20. Martin H, Procter DF. Pressure-volume measurements on dog bronchi. J Appl Physiol 1958; 13: 337-343. 